\title{
COMPARISON OF LASER SCANNING AND PHOTOGRAMMETRY AND THEIR USE FOR DIGITAL RECORDING OF CULTURAL MONUMENT CASE STUDY: BYZANTINE LAND WALLS-ISTANBUL
}

\author{
B.Bayram ${ }^{\text {a }}$, G. Nemli ${ }^{\text {b }}$, T. Özkan ${ }^{\text {c }}$, O.E. Oflaz ${ }^{\text {b, }}$, B. Kankotan ${ }^{\text {d }}$, İ. Çetin ${ }^{\text {a }}$
${ }^{a}$ YTU, Civil Engineering Faculty, Department of Geomatic Engineering, Division of Photogrammetry, Davutpasa Campus, 34210
Esenler, Istanbul, Turkey-(bayram@yildiz.edu.tr; icetin@yildiz.edu.tr)
${ }^{\mathrm{b}}$ Fatih Municipality, Survey and Project Department, 34080 Fatih, Istanbul, Turkey-(o.erhanoflaz@fatih.bel.tr, gulsen.nemli@gmail.com)
c Piksel Teknoloji Co. Yildiz Technical University Technopark B1, B204, 34210 Esenler, Istanbul, Turkey- (tozkan@pikselteknoloji.com)
d Galata Restoration Architecture, 34083 Fatih, Istanbul, Turkey - (bagiskankotan@gmail.com)

KEY WORDS: Cultural Heritage, Terrestrial Laser Scanning, Image matching, Photogrammetry, 3D Modeling

\begin{abstract}
:
3D modeling of cultural monuments is very crucial issue for preparing restoration projects. However, it has challenges such as data acquisition, preparation and processing. 3D modeling of objects can be time consuming and may include some difficulties due to the complexity of the structures. 3D terrestrial laser (TLS) scanning technique is one of the reliable and advantageous methods for 3D reconstruction of monuments. This technique is commonly acknowledged due to its accuracy, speed and flexibility. But the suitability and capability of this technique depends on proper usage, and good survey planning. Magnificent developments in highresolution digital sensor technologies leaded to manufacturing of new camera systems. Parallel to these innovations, development of computer systems and image processing techniques made enable to obtain multiple image-based 3D object models. In the presented study, TLS method has been compared to conventional photogrammetric and image-based dense matching methods. Automatic dense point creation has been realized by our developed algorithm and PIXEL-PHOTO software which generates 3D point clouds from stereo images. The reliability and encountered problems during point cloud measurement process have been discussed. The study area has been chosen as historical Byzantine Land Walls of Istanbul, which constitute a remarkable area defining the ancient city's historical peninsula.
\end{abstract}

\section{INTRODUCTION}

Historical structures and monuments are symbols of the cultural identity and they constitute the most important part of the cultural heritage (Grussenmeyer, et al., 2012; Vatan, et al., 2009). 3D modeling and continuously monitoring of historical objects is a crucial issue (Fritsch, et al., 2011; Al-kheder, et al., 2009). "According to UNESCO (1972), the geometric documentation can be defined as the action of acquiring, processing, presenting and registering the data necessary for the determination of the position, shape and size of a monument within a three-dimensional (3D) space and at a given moment in time. That is, such documentation records the present state of a heritage element, providing the basis for the study of its past" (Martínez, et al., 2015).

Objects can be monitored by several different techniques (Pesci, et al., 2012) such as conventional close range photogrammetry(Gruen et al., 2002), infrared thermography (IRT) (Clark, et al.,2003), image-based (Hutchinson and Chen, 2006), TLS (Pesci et al., 2011; Park, et al., 2007), digital photogrammetry (Bitelli, et al., 2007; Girelli, et al., 2005).

TLS is a popular and reliable method for heritage documentation (Rüther, et al., 2011). TLS systems are regarded to the standard method for recording cultural heritage (Christofori and Bierwagen, 2013). Interactive modelling at laser scanning systems and automatic generated point cloud by dense image matching is easier than conventional photogrammetric systems. Operator does photogrammetric evaluation on the plane at conventional method. Namely operator can't rotate in 3D space. Whereas model could be done by operator in 3D space (Demir, et al., 2004).

Along with TLS techniques, image-based approaches for 3D object modeling is important research topic for many applications (Aguilera, et al., 2009). Nowadays, low-cost close range photogrammetry became very popular for many researchers because of the resolution and inexpensiveness of new digital cameras (Barazzetti, et al., 2011). Stereo image matching and 3D object reconstruction is essential task for many applications (Hirschmueller, 2005). Image based approaches are available to create $3 \mathrm{D}$ geometric models by using a mathematical model from multiple 2D images and can be used for obtaining geometric surfaces of objects (Luhmann et al., 2007; El-Hakim, 2002). Detailed explanations about image based object reconstruction techniques can be found in (Remondino \& El-Hakim, 2006).

Dense stereo matching solutions are new and their results are reliable, applicable and precision is high. The density of created point clouds is almost equal to TLS techniques and they are cost effective (Hullo, et al., 2009). Image-based methods are convenient for affordable digital cameras and provide maximum quality with multiple overlapping stereo images and it is possible to create highly accurate $3 \mathrm{D}$ models of the objects by these methods. Digital photogrammetric approach based on image matching techniques can be taken as an alternative to expensive terrestrial laser scanners (Cabrelles, et al., 2010).

In this study, historical Byzantine Land Walls of Istanbul have been scanned with Faro Focus 3D scanner and north façade of the walls examined. The developed method, which creates 
dense point clouds from stereo images, has been compared with TLS and manual photogrammetric method.

\section{STUDY AREA}

"The Byzantine Land Walls of Istanbul are located at Topkap1 region of Istanbul. (Figure-1) Dating back to the reign of Theodosius II (408-450 AD), the "Land Walls" enclose the land boundaries of the Byzantine settlement. Due to their multiple defense systems consisting of a moat (taphros), outer terrace (parateichion), outer wall (mikron teichos), inner terrace (peribolos), and inner wall (mega teichos), the Land Walls are considered to be one of the greatest achievements of ancient military architecture. With UNESCO's inclusion of the monument and its surroundings on the World Heritage List in 1985, the remarkable significance of the Land Walls was internationally acknowledged" (Figure-2) (Çorakbaş, et al., 2014).

"During the Byzantine period, the Land Walls had already undergone several transformations - an indicator of their dynamic relationship with the urban fabric of the city and with the larger transformations of the Byzantine state. Furthermore, during the Ottoman conquest of the city, the Land Walls continued serving the capital as its urban limits and defenses. In the statement of the Outstanding Universal Value (OUV), the site was described as 'the area along both sides of the Theodosian land walls including remains of the former Blachernae Palace'. Moreover, in the OUV, it was underlined that "the 6,650 meter terrestrial wall of Theodosius II with its second line of defense, created in 447, was one of the leading references for military architecture"' (Çorakbaş, et al., 2014).

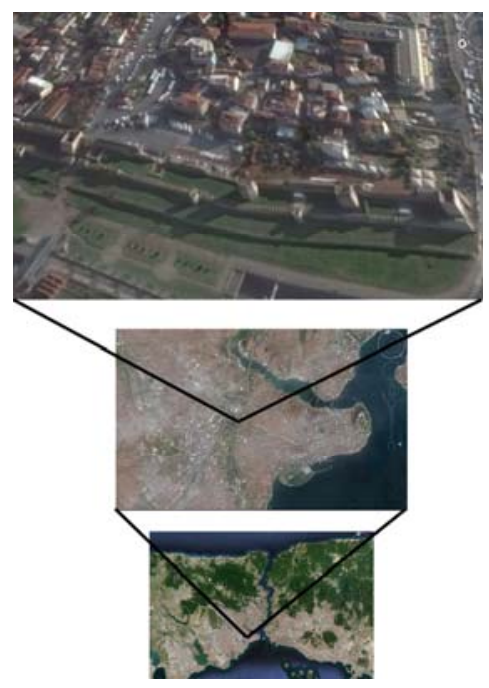

Figure 1. Study area

"The description of the Land Walls World Heritage Sites emphasizes the importance of the current layout of the walls resulting from modifications performed in the 7 th and 12th centuries and the presence of the quarter and the Palace of the Blachernae"(Çorakbaş, et al., 2014). The land walls situated within Block 1567/1 Parcel is listed as a 'cultural heritage to be preserved' by the order of Committee of Conservation of Cultural and Natural Heritage of Istanbul dated 06.01.1957 and issued 607.

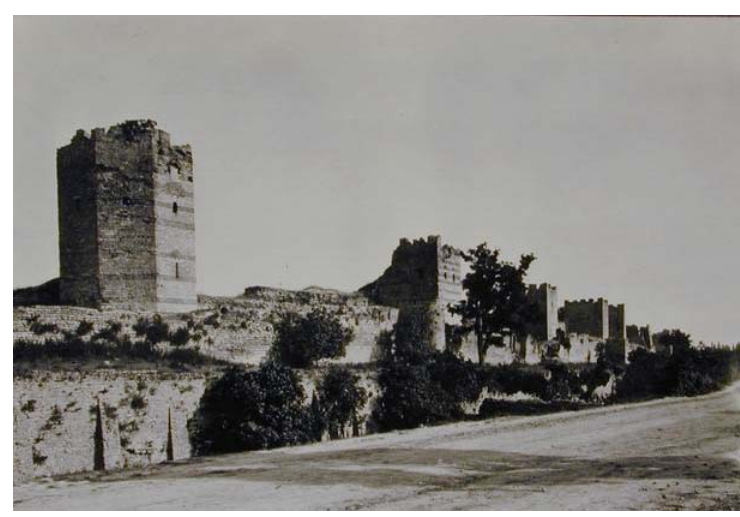

Figure-2 20. Century photograph of the Byzantine Land Walls of Istanbul [1]

\section{MATERIALS AND METHODS}

In this study, The Land Walls (The north facade of T61 Dungeons) has been scanned with Faro Focus 3D laser scanner. The Geomagic commercial software has been used to create 3D model of the façade. The instrument distributes the laser beam at a vertical range of $305^{\circ}$ and a horizontal range of $360^{\circ}$. The measurement rate is up to 976,000 points per second. Distance accuracy is up to $+/-2 \mathrm{~mm}$, its range is between $0.6 \mathrm{~m}$ and 120 $\mathrm{m}$ in daylight and it reaches up to $153 \mathrm{~m}$ in closed areas. 10.929.706 points were obtained from 133.797 .976 points after noise elimination. The photographs have been taken with 18 MP Canon 700D camera with $18-200 \mathrm{~mm}$ lens. One stereo pair has been used for conventional photogrammetric evaluation and automatic image-based methods for evaluation of the façade. The developed automatic image-based algorithm (PIXELPHOTO) has been used for dense 3D point cloud generation and 8.930 .064 points have been created.

\subsection{Laser Scanning and processing}

TLS measurements have been done into three mains steps, which are measurement of ground control points by geodetic survey, geo-referencing of scanned patches and modeling of the monument. Point clouds have been registered to the ground coordinate system by using ground control points. The scanning distance was 10 meters; the footprint size was $3 \mathrm{~mm}$ diameter. The original point cloud data has been used without any filtering and 3D mesh model of the facade generated. The scanning result and created 3D mesh model of TLS data are given in Figure-3-a, $b$ and the stereo pairs for photogrammetric evaluation are given in Figure-3-c, d.

\subsection{Conventional and automatic photogrammetric evaluation}

Photographing distance and base distances were $20 \mathrm{~m}$ and $2.5 \mathrm{~m}$ respectively. Photo scale has been calculated as 1/1240. Ground sample distance and overlapping ratio have been calculated as $0.584 \mathrm{~cm}$ and $85 \%$ respectively. The ground control points have been measured from point cloud data to create stereo model and to have same coordinate system for comparison steps (Figure4). Totally eleven control points have been used for photogrammetric evaluation. Ground control point plan has been given in Figure-4. In this study, Camera calibration parameters have not been used for manual photogrammetric assessment and dens matching steps to observe the distortion. 

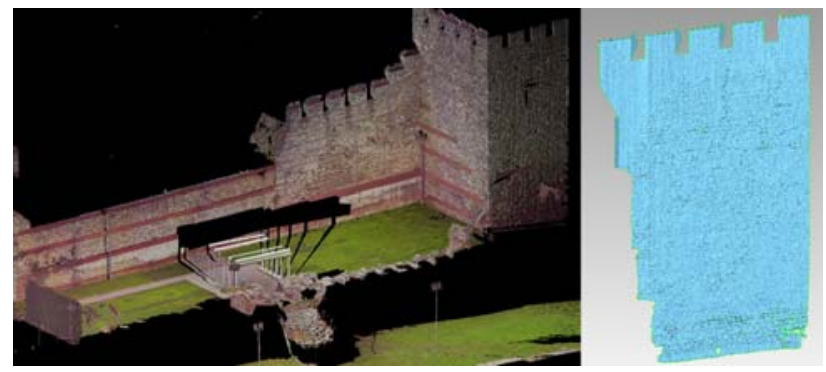

(a) Scanned walls

(b) Mesh model

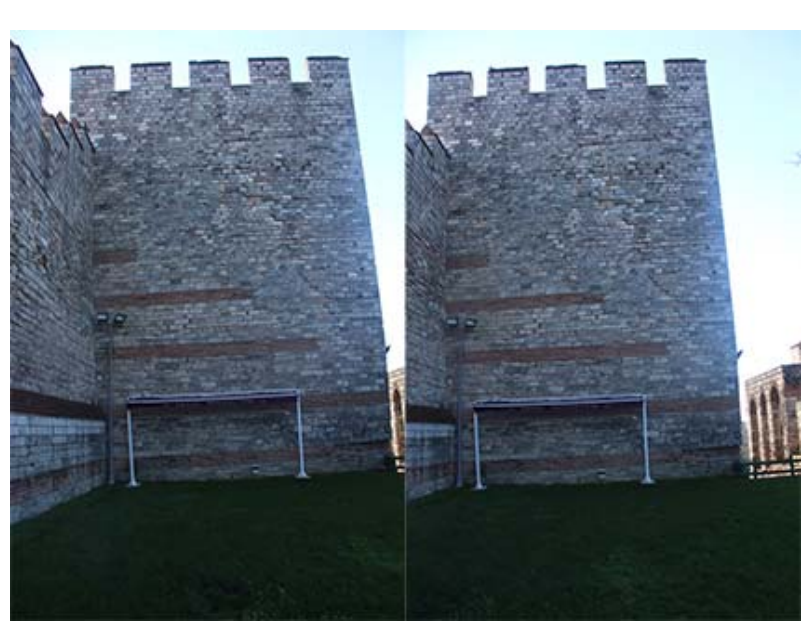

(c, d) Stereo pair

Figure-3 Scanned, mesh generated walls and stereo pair for photogrammetric evaluation

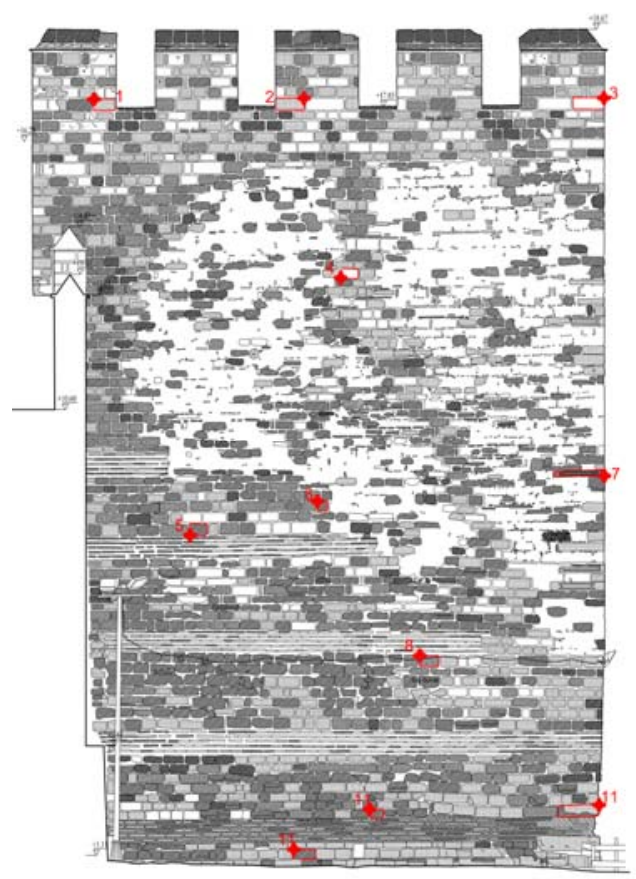

Figure-4 Ground control point plan
The demo version of PHOTOMOD commercial software has been used. Exterior and absolute orientation steps have been done by manually.

In the third step of the study, our developed PIXEL-PHOTO software has been used to create 3D point cloud and the same objects have been measured in Figure-5. The main flowchart of the developed algorithm has been given in Figure-5. The algorithm has been coded in .NET platform and EMGUCV [2] open source library has been used.

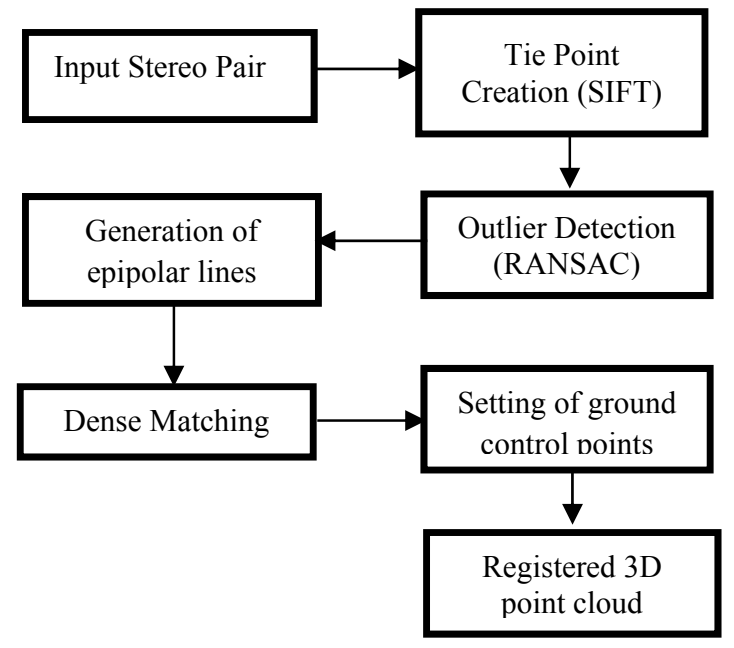

Figure-5 Flowchart of PIXEL-PHOTO algorithm

For automatic point cloud generation, well known SIFT (Love, 2004) key point creator has been used due to its scale and rotation invariance ability. Total 64.583 tie points have been generated (Figure-6-a). RANSAC algorithm (Fischler and Bolles, 1981) has been used to eliminate false matched points. The tie point matching accuracy was calculated in 0.10 pixel size. In the third step, the relative 3D rotations of photographs have been calculated and epipolar lines created. By realizing dense matching, unregistered 3D point clouds have been obtained. In the presented study 10.266 .068 points have been created. The ground control points have been taken from TLS data and set in to the PIXEL-PHOTO and as a result registered $3 \mathrm{D}$ point cloud has been generated (Figure-6-b).

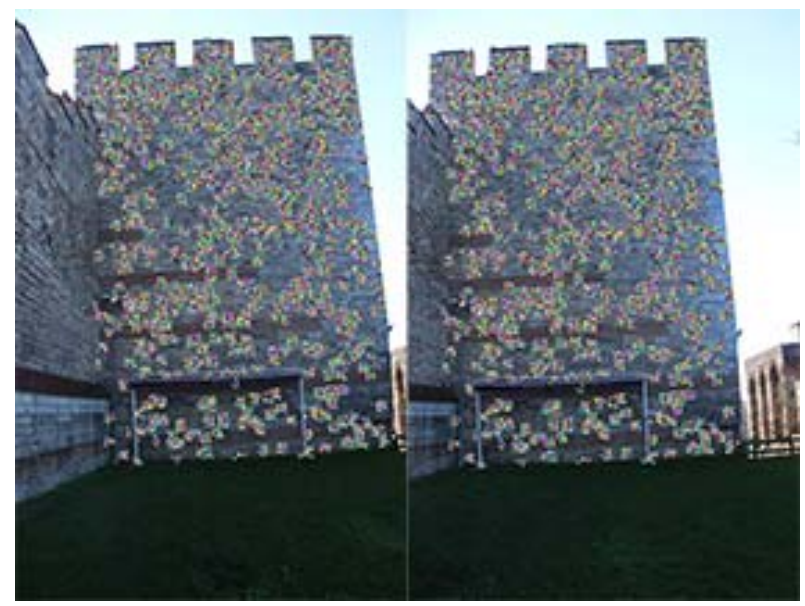

(a) Generated tie points 


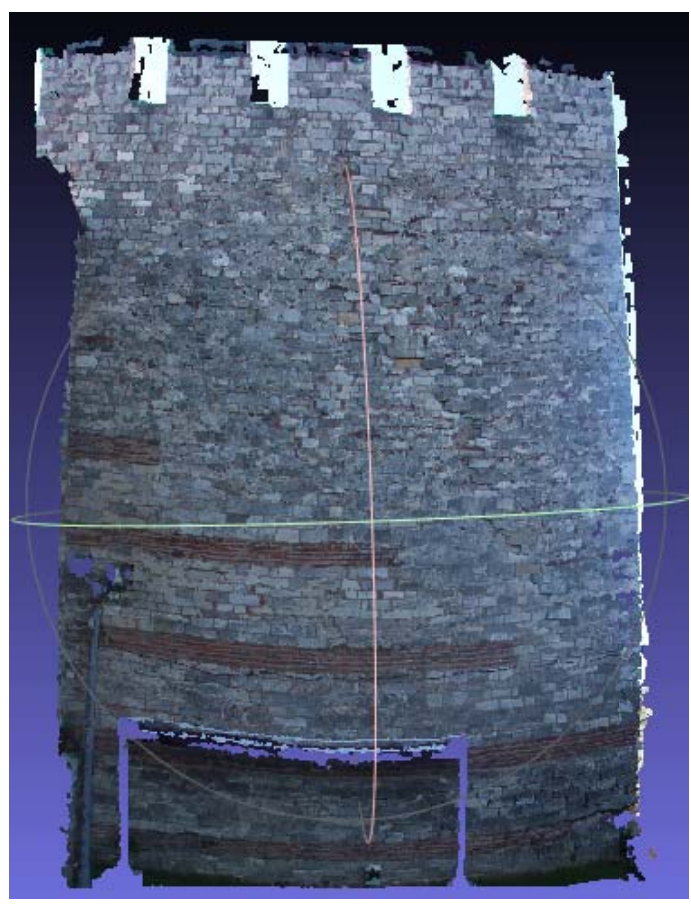

(b) $3 \mathrm{D}$ point cloud

Figure-6 Generated tie points and 3D point cloud

\section{COMPARISON METHODS OF TERRESTRIAL LASER SCANNING AND PHOTOGRAMMETY}

Eight stones have been taken as control objects and all sides of eight stones (A, B, C, D, E, F, H, I) have been measured and compared (Figure-7). The measurements have been done manually. Measurement plan of stones is given in Figure- 8 and results are given in (Figure-9, a, b, c). TLS data measurements are given in Table-1, Results of conventional photogrammetric results are given Table-2, and automatic generated point cloud measurements are given in Table-3.

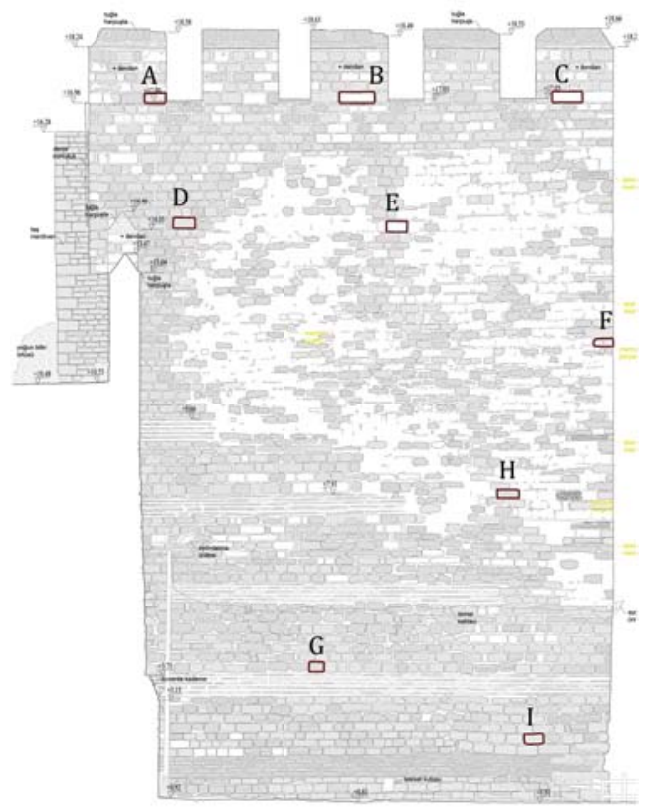

Figure-7 Measured stones

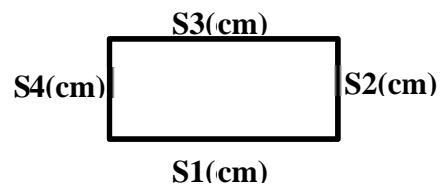

Figure-8 Measurement plan

\begin{tabular}{|c|c|c|c|c|c|}
\hline \multirow{4}{*}{ 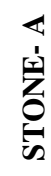 } & $\mathrm{S} 1$ & 44.128 & \multirow{4}{*}{ 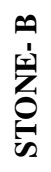 } & S1 & 75.973 \\
\hline & $\mathrm{S} 2$ & 17.493 & & $\mathrm{~S} 2$ & 19.945 \\
\hline & $\mathrm{S} 3$ & 40.708 & & S3 & 78.701 \\
\hline & S4 & 21.966 & & S4 & 18.340 \\
\hline \multirow{4}{*}{ 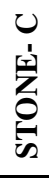 } & $\mathrm{S} 1$ & 63.868 & \multirow{4}{*}{ 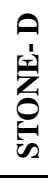 } & $\mathrm{S} 1$ & 46.186 \\
\hline & $\mathrm{S} 2$ & 22.768 & & $\mathrm{~S} 2$ & 23.411 \\
\hline & S3 & 60.731 & & S3 & 46.368 \\
\hline & S4 & 18.463 & & S4 & 21.008 \\
\hline \multirow{4}{*}{ 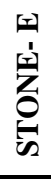 } & S1 & 45.468 & \multirow{4}{*}{ 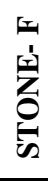 } & S1 & 38.094 \\
\hline & $\mathrm{S} 2$ & 30.830 & & $\mathrm{~S} 2$ & 16.435 \\
\hline & S3 & 39.346 & & S3 & 37.564 \\
\hline & S4 & 22.437 & & S4 & 13.663 \\
\hline \multirow{4}{*}{ 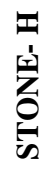 } & S1 & 47.015 & \multirow{4}{*}{ 占 } & $\mathrm{S} 1$ & 36.599 \\
\hline & $\mathrm{S} 2$ & 17.900 & & S2 & 21.224 \\
\hline & S3 & 49.165 & & S3 & 45.388 \\
\hline & S4 & 19.603 & & S4 & 22.844 \\
\hline
\end{tabular}

Table-1 TLS data measurements

\begin{tabular}{|c|c|c|c|c|c|}
\hline \multirow{4}{*}{ 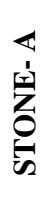 } & S1 & 46.601 & \multirow{4}{*}{ 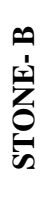 } & S1 & 80.200 \\
\hline & S2 & 23.613 & & S2 & 25.224 \\
\hline & S3 & 46.504 & & S3 & 79.302 \\
\hline & S4 & 21.966 & & S4 & 24.800 \\
\hline \multirow{4}{*}{ ט } & S1 & 69.000 & \multirow{4}{*}{ 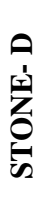 } & S1 & 48.296 \\
\hline & $\mathrm{S} 2$ & 24.010 & & S2 & 25.010 \\
\hline & $\mathrm{S} 3$ & 68.405 & & S3 & 47.700 \\
\hline & S4 & 24.500 & & S4 & 21.008 \\
\hline \multirow{4}{*}{ 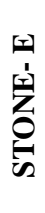 } & S1 & 47.610 & \multirow{4}{*}{ 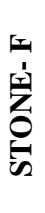 } & S1 & 43.379 \\
\hline & $\mathrm{S} 2$ & 24.814 & & S2 & 18.723 \\
\hline & $\mathrm{S} 3$ & 47.131 & & S3 & 35.211 \\
\hline & S4 & 22.437 & & S4 & 13.663 \\
\hline \multirow{4}{*}{ 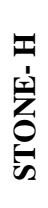 } & S1 & 50.400 & \multirow{4}{*}{ 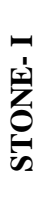 } & S1 & 39.423 \\
\hline & $\mathrm{S} 2$ & 21.100 & & S2 & 20.846 \\
\hline & $\mathrm{S} 3$ & 50.500 & & S3 & 43.400 \\
\hline & S4 & 20.900 & & S4 & 22.844 \\
\hline
\end{tabular}

Table-2 Conventional photogrammetric data measurements 


\begin{tabular}{|c|c|c|c|c|c|}
\hline \multirow{4}{*}{ 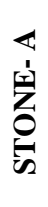 } & S1 & 45.598 & \multirow{4}{*}{ 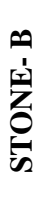 } & S1 & 77.446 \\
\hline & S2 & 23.353 & & S2 & 22.022 \\
\hline & S3 & 46.064 & & S3 & 77.842 \\
\hline & S4 & 20.297 & & S4 & 23.972 \\
\hline \multirow{4}{*}{ U } & S1 & 66.052 & \multirow{4}{*}{ 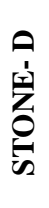 } & S1 & 48.879 \\
\hline & S2 & 21.112 & & S2 & 25.179 \\
\hline & S3 & 65.382 & & S3 & 48.059 \\
\hline & S4 & 20.469 & & S4 & 21.805 \\
\hline \multirow{4}{*}{ 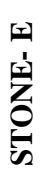 } & S1 & 47.518 & \multirow{4}{*}{ 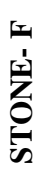 } & S1 & 42.613 \\
\hline & S2 & 23.385 & & S2 & 19.655 \\
\hline & S3 & 47.893 & & S3 & 40.615 \\
\hline & S4 & 22.351 & & S4 & 15.522 \\
\hline \multirow{4}{*}{ 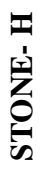 } & S1 & 44.47 & \multirow{4}{*}{ 年 } & S1 & 39.209 \\
\hline & S2 & 12.734 & & S2 & 20.754 \\
\hline & S3 & 44.639 & & S3 & 47.806 \\
\hline & S4 & 12.15 & & S4 & 19.563 \\
\hline
\end{tabular}

Table-3 Automatic generated point cloud data measurements

The comparison results are given in Table-4. In this table, L-IM column represents differences between TLS and automatically created point clouds, TLS-CP column represents differences between TLS and conventional photogrammetric measurements, and CP-IM column represents differences between automatically created point cloud and conventional photogrammetric evaluation results.

\begin{tabular}{|c|c|c|c|c|c|c|c|c|c|}
\hline & & $\begin{array}{l}\text { TLS- } \\
\text { IMM }\end{array}$ & $\begin{array}{l}\text { TLS- } \\
\text { CP }\end{array}$ & P-IM & & & $\begin{array}{l}\text { TLS- } \\
\text { IM }\end{array}$ & $\begin{array}{l}\text { TLS- } \\
\text { CP }\end{array}$ & CP-IM \\
\hline \multirow{4}{*}{ 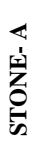 } & S1 & -1.470 & -2.473 & 1.003 & \multirow{4}{*}{ 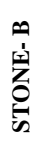 } & S1 & -2.120 & -4.227 & -2.107 \\
\hline & S2 & -5.860 & -6.120 & -0.260 & & S2 & -2.077 & -5.279 & -3.202 \\
\hline & S3 & -5.356 & -5.796 & -0.440 & & S3 & 0.682 & -0.601 & -1.283 \\
\hline & S4 & 0.774 & 0.000 & -0.774 & & S4 & -5.223 & -6.460 & -1.23 \\
\hline \multirow{4}{*}{ 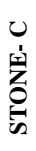 } & S1 & -4.166 & -5.132 & -0.966 & \multirow{4}{*}{ 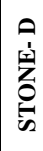 } & S1 & -2.693 & -2.110 & 0.583 \\
\hline & S2 & 0.888 & -1.242 & -2.130 & & S2 & -1.768 & -1.599 & $0.16 \mathrm{~s}$ \\
\hline & S3 & -6.133 & -7.674 & -1.541 & & S3 & -1.691 & -1.332 & 0.359 \\
\hline & S4 & -4.348 & -6.037 & -1.689 & & S4 & -0.797 & 0.000 & 0.797 \\
\hline \multirow{4}{*}{ 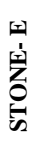 } & $\mathrm{S} 1$ & -2.050 & -2.142 & -0.092 & \multirow{4}{*}{ 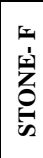 } & S1 & -4.519 & -5.285 & -0.766 \\
\hline & S2 & 6.905 & 6.016 & -0.889 & & S2 & -3.220 & -2.288 & 0.932 \\
\hline & S3 & -8.547 & -7.785 & 0.762 & & S3 & 1.635 & 2.353 & 0.718 \\
\hline & S4 & 0.086 & 0.000 & -0.086 & & S4 & -0.040 & 0.000 & 0.04 \\
\hline \multirow{4}{*}{ 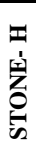 } & S1 & -5.390 & -3.385 & 2.005 & \multirow{4}{*}{ 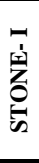 } & S1 & -2.610 & -2.824 & -0.214 \\
\hline & S2 & -0.482 & -3.200 & -2.719 & & S2 & 0.470 & 0.378 & -0.092 \\
\hline & S3 & -3.106 & -1.335 & 1.771 & & S3 & -2.418 & 1.988 & 4.406 \\
\hline & S4 & -0.192 & -1.297 & -1.104 & & S4 & 0.224 & 0.000 & -0.224 \\
\hline \multicolumn{2}{|c|}{ Avrg } & -2.4 & -2.975 & -0.572 & \multicolumn{2}{|c|}{ Avrg } & -1.635 & -1.705 & -0.070 \\
\hline
\end{tabular}

Table-4 Comparison results

\section{RESULTS AND DISCUSSIONS}

In this study, the north façade of The Byzantine Land Walls of Istanbul has been in 3D modeled. The CAD output of the monument is given in Figure-9.

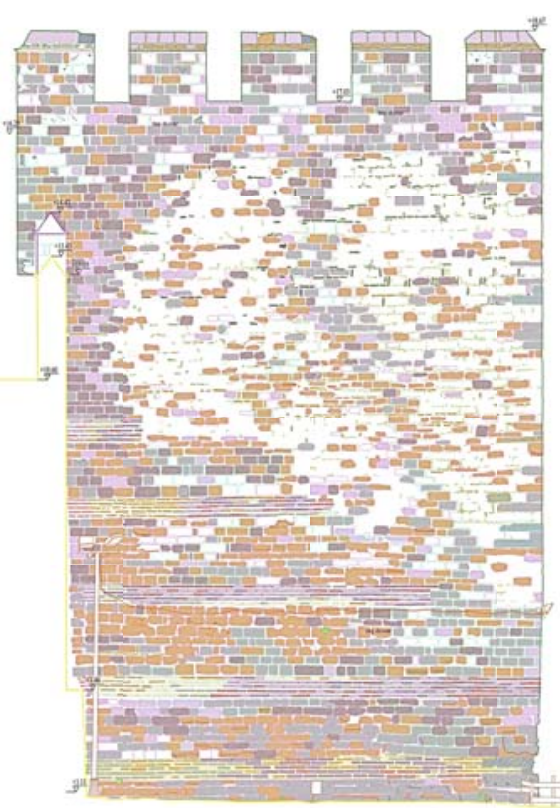

Figure-9 CAD output of the north façade of the Byzantine Land Walls of Istanbul

Three different measurement techniques have been applied and the results compared. These are TLS, conventional photogrammetric and automatic image matching-based approaches. The last method has been developed by authors and based on automatic point cloud generation from stereo photographs by using dense image matching technique. TLS survey for north façade has been completed in seven hours, photographing time was shorter and took two hours. The CAD model of the façade has been created by manual digitizing from preprocessed TLS data. It consisted of two main steps. These were elimination of noisy point cloud data and mesh creation. Thus, basic data has been prepared for manual digitizing phase. Due to big volume of the raw point cloud data, special computer system (10 GPGPU server, CPU: 4x E7-4820 v2 @ 2.00GHz (8 core/socket), 64 MB RAM, GPGPU: 4x Tesla K20X (2688 cores)) has been used. Standard computers with i7 processor was not able to process this amount of point cloud data. Stereo photographs have been taken with Canon 700D non-metric camera with $18 \mathrm{MB}$ resolution and with $0.584 \mathrm{~cm}$ ground sample distance.

The object distance has been calculated as $20 \mathrm{~m}$ to cover the facade. The photographs have been taken parallel rotated and oblique. The calculated exterior orientation parameters are given in Table-5.

\begin{tabular}{|c|c|c|}
\hline & Left photo & Right photo \\
\hline$\omega$ (in grad) & 13.6390107 & 12.87067 \\
\hline$\psi($ in grad) & -1.020404 & 1.172842 \\
\hline K (in grad) & -4.893236 & -4.999772 \\
\hline
\end{tabular}

Table-5 exterior orientation parameters

Absolute orientation parameters of left photo are: $\mathrm{X}_{0}=573$, $357565 \mathrm{~m} ; \mathrm{Y}_{0}=348,899456 \mathrm{~m} \mathrm{Z}_{0}=69,404525 \mathrm{~m}$; for right photo: $\mathrm{X}_{0}=576,281393 \mathrm{~m} ; \mathrm{Y}_{0}=348,876567 \mathrm{~m} \mathrm{Z}_{0}=69,360320 \mathrm{~m}$. 
Since the ground control points were taken from TLS point cloud data, the absolute orientation parameters have been calculated in laser scanning coordinate system.

In this study, Standard laptop computer (i5 processor, $2.4 \mathrm{GHz}$, 8GB RAM, 64 bit operating system) has been used to create automatic point cloud by using developed PIXEL-PHOTO algorithm. Automatic point cloud creation time for two stereo photographs has been calculated as $1.5 \mathrm{~min}$.

Eight stones with all sides have been measured with three different methods. As a result, average differences have been calculated as $2.02 \mathrm{~cm}$ between L-IM, $2.34 \mathrm{~cm}$ between L-CP and $0.32 \mathrm{~cm}$ between CP-IM. As it can be seen from the results, differences between manual photogrammetric and automatic point cloud generation methods are almost equal. Although the measurements have been done by different operators, the results are consistent and differences between TLS method and photogrammetric methods have been calculated very close.

In this study, several difficulties have been observed during processing of TLS data. The most time consuming part TLS processing was elimination of noisy point cloud data. 10.929.706 points have been achieved from 133.797.976 raw points. It has been obviously seen that elimination of noisy data requires expertise and good focusing for interpretation. Data contours were messy and unclear. False reflected points have been observed. Their size reached $15-20 \mathrm{~cm}$ in some regions. False reflected points caused erroneous mesh model. Therefore, operator had interpretation and digitizing difficulties. Additional mesh editing has been applied to overcome this problem. Furthermore, in some regions, only lower contour of stone could have been defined clearly. But, identification of top contour was almost unable to determine (Figure-10). Another unavoidable problem was shadows. They have been brought other difficulties during digitizing. They made the contours of stones fuzzy and it caused digitizing errors and the size of objects have been measured and digitized erroneous. It has been seen that if the operator cannot give full attention during digitizing, this problem can decrease quality of survey also restoration project. Because of structure and position of the stones, holes have been observed. To fill these holes different algorithms (linear, curvative) have been used. But, it cannot be said that these hole-filling methods guarantee to obtain true object model in filled regions (Temizer, et al., 2013).
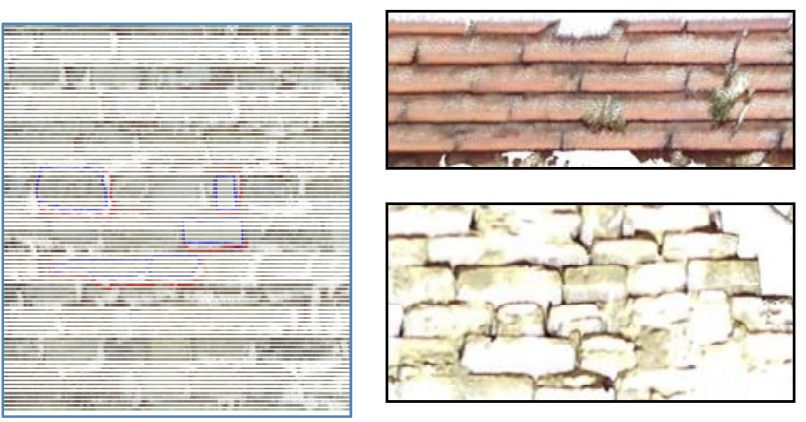

Figure-10 Occurred problems during digitizing of laser scanner data.

Parallel rotated and oblique photographs caused scale changing problem between top and bottom of the façade. However, if Table- 4 and Figure- 7 are taken into account, the location of the stone-A is at the top of the façade and stone-I is at the bottom of the façade. Average differences between TLS data and conventional photogrammetric evaluations for the stone-A and the stone-I are $3.597 \mathrm{~cm}$ and $0.115 \mathrm{~cm}$ respectively. The same results have been observed in image-based method too. Average differences between TLS data and developed method for the stone-A and stone-I are $2.978 \mathrm{~cm}$ and $0.969 \mathrm{~cm}$ respectively. These results show the effect of scale changing on evaluation accuracy obviously. As it has been mentioned above, the camera calibration step has not been done for both manual and image-based methods. Therefore this differences include also distortion error.

The results of developed algorithm (PIXEL-PHOTO) can be found reliable according to average distance differences between TLS-IM $(2.34 \mathrm{~cm})$ and TLS-CP $(2.34 \mathrm{~cm})$. As a result, in terms of data collection, PIXEL-PHOTO algorithm is inexpensive and faster than TLS method. The developed method's point cloud generation density has been found enough to meet necessary requirements. Although only two stereo photographs have been used in this study, processing of multiple photos is also possible by this algorithm.

Many researches propose to combine and integrate both TLS and photogrammetric methods (Rizzi, et al., 2011; Lerma et al, 2010). The generated point clouds of developed approach can be used also in this way. They can be integrated easily with TLS data to fill the holes without applying any hole-filling algorithm.

The proposed image-based approach can be used not only for 3D modeling of historical monuments also for historical buildings and tangible historical heritages. In addition automatically created point cloud data can be superimposed directly on its original photographs to improve interpretation quality, so especially break lines, damaged parts of historical objects can be defined and recorded for restoration projects which may not be possible to determine with TLS technique.

In the future, we plan to create 3D model of historical buildings and tangible cultural heritage and to integrate with Meshlab open source point cloud and mesh processing software.

\section{REFERENCES}

Aguilera Diego González, Gonzálvez Pablo Rodríguez, Lahoz Javier Gómez An automatic procedure for co-registration of terrestrial laser scanners and digital cameras, ISPRS Journal of Photogrammetry and Remote Sensing 64 (2009) 308-316.

Al-kheder Sharaf, Al-shawabkeh Yahya Haala Norbert, Developing a documentation system for desert palaces in Jordan using 3D laser scanning and digital photogrammetry, Journal of Archaeological Science 36 (2009) 537-546.

Barazzetti, L., Remondino, F., and Scaioni, M. (2011). Automated and accurate orientation of complex image sequences. International Archives of the Photogrammetry, Remote Sensing and Spatial Information Sciences, Volume XXXVIII-5/W16, ISPRS Trento 2011 Workshop, Trento, Italy, pp. $277-284$.

Bitelli G., Girelli V.A., Marziali M., Zanutta A., Use of historical images for the documentation and the metrical study of cultural heritage by means of digital photogrammetric techniques, in: A. Georgopoulos (Ed.), Proceedings of CIPA, XXI Symposium, Athens, Greece, October 1-6, 2007. 
Cabrelles M., Seguí A. E., Navarro S., Galcerá S., Portalés C., Lerma J. L., 3D photorealistic modelling of stone monuments by dense image matching, International Archives of Photogrammetry, Remote Sensing and Spatial Information Sciences, Vol. XXXVIII, Part 5 Commission V Symposium, Newcastle upon Tyne, UK. 2010, p.121-124.

Christofori E., Bierwagen J., Recording cultural heritage using terrestrial laserscanning -Dealing with the system, the huge datasets they create and ways to extract the necessary deliverables you can work with, International Archives of the Photogrammetry, Remote Sensing and Spatial Information Sciences, Volume XL-5/W2, 2013 XXIV International CIPA Symposium, 2 - 6 September 2013, Strasbourg, France, p. 183188.

Clark M.R., McCann D.M., Forde M.C., Application of infrared thermography to the non-destructive testing of concrete and masonry bridges, NDT \& E Int. 36 (4) (2003) 265-275.

Çorakbaş K. F., Aksoy A., Ricci A., A Report of Concern On The Conservation Issues Of the Istanbul Land Walls World Heritage Site, Istanbul, (2014).

Demir N., Bayram B., Alkis Z., Helvaci C., Cetin I., Voegtle T., Ringle K., Steinle E. (2004), Laser Scanning for Terrestrial Photogrammetry, Alternative System or Combined with Traditional System (poster), XXth Congress International Society for Photogrammetry and Remote Sensing, Proceedings, Commission V, p. 193 - 197, 12-23 July ， 2004,Istanbul, Turkey.

El-Hakim, S. (2002). Semi-automatic 3D reconstruction of occluded and unmarked surfaces from widely separated views. In International Archives of the Photogrammetry, Remote Sensing and Spatial Information Sciences, pp. 143-148.

Fischler M. A., Bolles R. C.. Random Sample Consensus: A Paradigm for Model Fitting with Applications to Image Analysis and Automated Cartography. Comm. of the ACM, Vol 24, pp 381-395, 1981.

Girelli V.A., Tini M.A., Zanutta A., Traditional and unconventional photogrammetric techniques formetrical documentation of cultural heritage:the example of the "Rolandino dei Passaggieri" Tomb (St. Domenico Square) survey in Bologna, in: S. Dequal (Ed.), Proceedings of CIPA, XX Symposium, Torino, Italy, September 26-01 October, 2005.

Gruen, A., Remondino, F., Zhang, L., 2002. Reconstruction of the Great Buddha of Bamiyan, Afghanistan. International Archives of Photogrammetry and Remote Sensing XXXIV-5, Corfu, Greece, pp. 363-368.

Grussenmeyer, P., Alby, E., Landes, T., Koehl, M., Guillemin, S., Hullo, J.-F., Assali, P., and Smigiel, E. (2012). Recording Approach of Heritage Sites based on Merging Point Clouds from High Resolution Photogrammetry and Terrestrial Laser Scanning. In International Archives of the Photogrammetry, Remote Sensing and Spatial Information Sciences, (Melbourne, Australia), pp. 553-558.

Fritsch, D., Khosravani, A.M., Cefalu, A., and Wenzel, K. (2011). Multi-Sensors and Multiray Reconstruction for Digital Preservation. In Photogrammetric Week '11, Ed. D. Fritsch, (Wichmann, Berlin/Offenbach), pp. 305-323.
Hirschmueller, H. (2005). Accurate and efficient stereo processing by semi-global matching and mutual information. In Computer Vision and Pattern Recognition, 2005. CVPR 2005. IEEE Computer Society Conference on, pp. 807-814.

Hullo J. F., Grussenmeyer P., Fares S., Photogrammetry and dense stereo matching approach applied to the documentation of The cultural heritage site of kilwa (Saudi Aarabia), 22nd CIPA Symposium, October 11-15, 2009, Kyoto, Japan (http://cipa.icomos.org/fileadmin/template/doc/KYOTO/1321.pdf)

Hutchinson T.C., Chen Z.Q., Improved image analysis for evaluating concrete damage, J. Comput. Civil Eng. 20 (3) (2006) 210-216.

Lerma, J. L., Navarro, S., Cabrelles, M., Villaverde, V., 2010. Terrestrial laser scanning and close range photogrammetry for 3D archaeological documentation: the upper palaeolithic cave of Parpalló as a case study. Journal of Archaeological Science, 37(3), pp. 499-507.

Lowe David G., US Patent 6,711,293 (March 23, 2004). Provisional application filed March 8, 1999. Asignee: The University of British Columbia.

Luhmann, T., Robson, S., Kyle, S., and Hartley, I. (2007). In Close Range Photogrammetry: Principles, Techniques and Applications, (Whittles, Dunbeath, UK), pp. 266-292, 449.

Martínez Santiago, Juan Ortiz, Gil M Luz, Geometric documentation of historical pavements using automated digital photogrammetry and high-density reconstruction algorithms, Journal of Archaeological Science 53 (2015) 1-11.

Mueller-Wiener W. Bildlexicon zur Topographie Istanbuls. Byzantion-Konstantinopels-Istanbul bis zum Beginn des 17 Jahrhunderts. Tuebingen 1977.

Park H.S., Lee H.M., Adeli H., A new approach to health monitoring of structures: terrestrial laser scanning, Comput. Aided Civil Infrastructure Eng. 22 (1) (2007) 19-30.

Pesci A., Casula G., Boschi E., Laser scanning the Garisenda and Asinellitowers in Bologna (Italy): detailed deformation patterns oftwo ancientleaning buildings,J. Cultur. Heritage 12 (2) (2011) 117-127.

Pesci A., Bonali E., Galli C., Boschi E., Laser scanning and digital imaging for the investigation of an ancient building: Palazzo d'Accursio study case (Bologna, Italy), Journal of Cultural Heritage 13 (2012) 215-220.

Remondino, F., and El-Hakim, S. (2006). Image-based 3D Modelling: A Review. Photogramm. Rec. 21, pp. 269-291.

Rizzi A., Baratti G., Jiménez B., Girardi S., Remondino F., 3D Recording for 2D delivering - The Employment Of 3D Models for Studies And Analyses - , International Archives of the Photogrammetry, Remote Sensing and Spatial Information Sciences, Volume XXXVIII-5/W16, 2011, ISPRS Trento 2011 Workshop, 2-4 March 2011, Trento, Italy, p. 301-309.

Rüther, H., Held, C., Bhurtha, R., Schröder, R., and Wessels, S. (2011). Challenges in Heritage Documentation with Terrestrial Laser Scanning. In Proceedings of AfricaGeo, 14p. 
Temizer T., Nemli G., Ekizce E., Ekizce A., Demir S., Bayram B., Askin F.H A. Cobanoglu V., Yilmaz H. F. (2013), 3D Documentation Of A Historical Monument Using Terrestrial Laser Scanning Case Study: Byzantine Water Cistern, Istanbul, International Archives of the Photogrammetry, Remote Sensing and Spatial Information Sciences, Volume XL-5/W2, 2013 XXIV International CIPA Symposium, 2 - 6 September 2013, Strasbourg, France, p.623-628.

UNESCO, 1972. Photogrammetry Applied to the Survey of Historical Monuments, of Sites and to Archaeology. In: UNESCO Editions.

Vatan Meltem, Selbesoğlu M. Oğuz, Bayram Bülent (2009), The Use of 3D Laser Scanning Technology in Preservation of Historical Structures, XIIIth Scientific Technical Conference REMO2009 - Repair, Conservation and Strengthening of Traditionally Erected Buildings and Historic Buildings, p.659669, 2 - 4 December 2009, Wroclaw, Poland.

\section{Internet references}

[1] www.archnet.org (accessed on 10.01.2015)

[2] http://www.emgu.com/wiki/index.php/Main_Page (accessed on 18.12 .2015 )

\section{ACKNOWLEDGEMENTS}

The authors wish to thank SVR Information Technologies Company that they provided their system to the study for processing laser scanner data, Prof. Dr. Kemal Kutgün Eyüpgiller (Istanbul Technical University) for supporting the report of Art History and Galata Restoration-Architecture Co. for survey and supporting of study. 